\title{
Relationship between temporomandibular disorder symptoms signs and Burnout syndrome among dentistry students
}

\author{
Relação entre sinais e sintomas de disfunção temporomandibular e de síndrome de Burnout \\ em estudantes de odontologia
}

Laís Valencise Magri ${ }^{1}$, Melissa Oliveira Melchior ${ }^{1}$, Larissa Jarina1, Flávia Fanchiotti Simonaggio¹, César Bataglion ${ }^{1}$

DOI 10.5935/1806-0013.20160065

\section{ABSTRACT}

BACKGROUND AND OBJECTIVES: Temporomandibular disorder and Burnout syndrome are influenced by emotional factors. This study aimed at prospectively evaluating Burnout syndrome dimensions and their relationship with temporomandibular disorder signs and symptoms in a sample of dentistry graduating students.

METHODS: Sample was made up of dentistry graduating students $(23 \pm 2.5$ years), who have answered the Maslach Burnout Inventory questionnaire, students survey, and the ProDTMMulti. Questionnaires were answered once a year, considering first, second and third year of the course (2013/2014/2015). Statistical analysis has compared Burnout syndrome dimensions between genders and has tested their correlation with total ProDTMMulti score, as well as variations between scores of this syndrome dimensions along the years by gender.

RESULTS: Considering total sample, there has been increase in risk zone frequency for Burnout syndrome as years went by. There has been significant difference between males and females for emotional exhaustion in the three evaluated years $(\mathrm{p}=0.002, \mathrm{p}=0.003, \mathrm{p}=0.01$, respectively) and also for disbelief in the last year $(\mathrm{p}=0.02)$, being higher for females. There has been significant correlation of ProTDMMulti scores and emotional exhaustion among females in the first and second evaluated years ( $\mathrm{p}=0.0004, \mathrm{p}=0.04$ ).

CONCLUSION: It seems to be correlation between emotional exhaustion and perception of temporomandibular signs and symptoms among females, and a trend to Burnout syndrome dimensions scores increase as course progressed.

Keywords: Burnout syndrome, Comorbidity, Temporomandibular disorder syndrome.

1. Universidade de São Paulo, Faculdade de Odontologia de Ribeirão Preto, Departamento de Odontologia Restauradora, Ribeirão Preto, SP, Brasil.

Submitted in May 18, 2016.

Accepted for publication in August 22, 2016.

Conflict of interests: none - Sponsoring sources: Conselho Nacional de Pesquisa (CNPq), by means of scholarship granting, Programa Institucional de Bolsas de Iniciaçáo científica (PIBIC).

Correspondence to:

Departamento de Odontologia Restauradora, Faculdade de Odontologia de Ribeirăo Preto (USP). Avenida do Café $(s / n)$

14040-904 Ribeirão Preto, SP, Brasil.

E-mail: laisvmagri@gmail.com

(C) Sociedade Brasileira para o Estudo da Dor

\section{RESUMO}

JUSTIFICATIVA E OBJETIVOS: A disfunção temporomandibular e a síndrome de Burnout são influenciadas por fatores emocionais. O objetivo deste estudo foi analisar de forma prospectiva as dimensôes da síndrome de Burnout, e sua relação com a percepçáo dos sinais e sintomas de disfunção temporomandibular em uma amostra de estudantes de graduação em Odontologia.

MÉTODOS: A amostra foi composta por alunos de graduação em odontologia ( $23 \pm 2.5$ anos), os quais responderam aos questionários Inventário de Burnout de Maslach - versão estudantes e o ProDTMMulti. Os questionários foram respondidos anualmente, considerando-se o primeiro, segundo e terceiro ano do curso (2013/2014/2015). A análise estatística comparou as dimensôes da síndrome de Burnout entre os gêneros e testou a sua correlação com o escore total do ProDTMMulti, bem como a variação entre os escores das dimensóes dessa síndrome ao longo dos anos por gênero.

RESULTADOS: Considerando a amostra total houve aumento na frequência da zona de risco para a síndrome de Burnout com o passar dos anos. Observou-se diferença significativa entre homens e mulheres para exaustáo emocional nos três anos avali$\operatorname{ados}(\mathrm{p}=0,002, \mathrm{p}=0,003, \mathrm{p}=0,01$, respectivamente) e ainda para a descrença no último ano $(\mathrm{p}=0,02)$, sendo mais altos para as mulheres. Houve correlação significativa dos escores do ProDTMMulti com a exaustão emocional nas mulheres no primeiro e segundo ano avaliados $(\mathrm{p}=0,0004, \mathrm{p}=0,04)$.

CONCLUSÁO: Parece existir uma correlação entre a exaustáo emocional e a percepção de sinais e sintomas de disfunção temporomandibular no gênero feminino e uma tendência de aumento dos escores das dimensôes da síndrome de Burnout com a progressão do curso.

Descritores: Comorbidade, Esgotamento profissional, Síndrome da disfunção da articulação temporomandibular.

\section{INTRODUCTION}

Temporomandibular disorder (TMD) is a collective term for a painful musculoskeletal syndrome affecting masticatory muscles, temporomandibular joint (TMJ) and associated structures, orofacial, and others. Epidemiologic studies point that $75 \%$ of the population have had at least one TMD sign and $33 \%$ at least one symptom ${ }^{1,2}$. Stress and excessive work- 
load may be risk factors for TMD, which has high prevalence of signs and symptoms in the Brazilian population ${ }^{3}$. Major signs and symptoms associated to this condition are: jaw movement limitation, joint noises and pain on face muscles and/or pre-auricular region ${ }^{4}$.

TMD patients may also have stress-related disorders, characterized by somatic and psychological changes such as fatigue, sleep disorders, anxiety and depression ${ }^{5,6}$. So, previous studies have shown that TMD patients have higher levels of stress, depression and anxiety, as compared to healthy control groups, and that some TMD symptoms and orofacial pain may be just somatic manifestations of emotional stress ${ }^{7-10}$. Also, TMD patients seem to have high levels of plasma cortisol/creatinine and of 17-hydroxisteroid in the urine, showing a high level of anxiety ${ }^{11}$.

TMD has major impact on quality of life and should be treated in a multidisciplinary manner. For such, it is critical good planning, associated to thorough anamnesis, including patients' medical and dental history, physical and extraoral evaluation. For being a condition with general clinical manifestations, it should be treated with a broader view and, if necessary, additional investigations should be included to help diagnosis and prognosis, ${ }^{2,4}$. Its multifactorial etiology is influenced by biopsychosocial aspects and for such it is important to quantify the frequency and severity of signs and symptoms, based on patients' perception. De Felicio, Melchior \& Da Silva ${ }^{13}$ have developed a protocol called Protocol for Multiprofessional Centers to Determine Temporomandibular Disorders Signs and Symptoms (ProDTMMulti), based on symptoms most frequently found in the literature and on situations causing the worst discomfort ${ }^{12}$.

This protocol was validated based on the Helkimo Clinical Disorder Index and aims at complementing clinical evaluation with information given by patients themselves in a measurable way.

According to Maslach et al., Burnout syndrome (BS) is characterized by psychological depletion resulting from chronic interpersonal stressors in the working/studying environment and is characterized by a triad: emotional exhaustion, depersonalization (or cynicism) and decreased personal achievement (or professional effectiveness) ${ }^{14}$. Emotional reaction to stressor situations leads to decreased motivation, interest and professional skills, generating severe negative individual, social, professional and family consequences. The prevalence of BS in healthcare professionals is high, ranging between 30 and $47 \%{ }^{15,16}$. In Brazil, general prevalence considering different working areas is approximately $10 \%{ }^{17}$.

There are different tools aiming at identifying the syndrome, among them the Maslach Burnout Inventory (MBI), which is a self-applicable questionnaire, validated for clinical research, gold-standard for signs and symptoms screening and which encompasses clinical manifestation criteria of the three BS dimensions (emotional exhaustion, cynicism and professional effectiveness). Schaufeli et al. have expanded BS concept to all occupational groups, including students. Excessive study loads associated to individual demands lead to clinical pre- sentation involving discouragement, apathy, social exclusion and exhaustion ${ }^{18}$.

This syndrome is associated to physiological changes related to chronic stress, especially neuroendocrine changes of the hypothalamic-pituitary-adrenal axis, thus being frequent the simultaneous presence of other mental health conditions, such as depression, alcohol and other substances abuse, risk for suicide and obsessive and anxiety disorders ${ }^{19-21}$. BS diagnostic criteria are well established and should encompass the three already mentioned dimensions: high emotional exhaustion and belief and low professional effectiveness evaluated by means of MBI and specialized professional evaluation. When the syndrome is overlapped with other psychiatric comorbidities, medical investigations and approaches able to act on both conditions are needed ${ }^{21}$.

Campos \& Maroco have developed a transcultural adaptation of the Portuguese version for students and have concluded that this version had high validity and reliability ${ }^{22}$. Current interest in this syndrome has enhanced its field of study. From early investigations centered on health professionals, it is being expanded to other professional fields and, more recently, there are studies with students. BS in this population refers to exhaustion feeling due to study demands, with consequent cynicism with regard to their activity and incapacity to perform such function, which leads to professional ineffectiveness feeling, that is, that teaching is not yielding useful learning for their professional qualification ${ }^{18,22}$.

Different studies have been carried out to evaluate BS in university students, especially those from the health $\operatorname{area}^{23-25}$. Campos et al. have carried out a study where they concluded that the prevalence of BS among dentistry students was high in the studied sample, being significant the relationship of the syndrome and students' performance, drug consumption due to studies and thoughts about quitting the course ${ }^{23}$. Humphris et al. have found a high emotional exhaustion level among students of the first year of dentistry from seven European universities ${ }^{24}$. Pöhlmann et al. have investigated BS in dentistry students of German and Swiss universities and have found that one third of them had characteristics of this syndrome ${ }^{25}$.

This study aimed at prospectively evaluating BS dimensions, as well as their relationship with TMD signs and symptoms perception in a sample of dentistry graduating students.

\section{METHODS}

This is a longitudinal, prospective, observational cohort study. Convenience sample was made up of dentistry graduating students, aged between 17 and 28 years and mean age of $23 \pm 2.5$ years, regardless of gender. Students were annually evaluated considering the first, second and third year of the course (2013, 2014 and 2015). This dentistry course lasts five years, so our results are preliminary and consider data collected in the first three stages. Inclusion criteria were: being dentistry graduating student starting in 2013 , be part of the 
above-mentioned age group. Exclusion criteria were: students with neurological disorders, students with previous diagnosis of psychiatric diseases. All participants have signed the Free and Informed Consent Term (FICT).

Students were submitted to MBI - student survey (MBI-SS) and ProDTMMulti questionnaires, and investigators were previously trained to apply the evaluation tools ${ }^{13,22}$. The first questionnaire is made up of three investigating items: emotional exhaustion (EE), cynicism (CI) and professional effectiveness (PE). Each item is made up of questions representing emotional status, interest/mood and ability to perform students' tasks with competence, respectively. Each answer is scored based on a Likert scale, which is a psychometric scale often used in opinion or self-perception questionnaires which varies from zero to six, being: $0-$ never, 1 - almost never, 2 - sometimes, 3 - regularly, 4 - very often, 5 - almost always and 6 - always. Total EE score above 4.8, CI score above 2.5 and PE below 4.17, according to parameters established by Loretto, Martins \& Abatyguara ${ }^{26}$, is indicative of $\mathrm{BS}^{26}$. These authors use the following names: presence, risk and absence of BS. It is relevant to stress that "indicative of presence" does not mean disease diagnosis. So, throughout this study we shall use these names, since this was the reference article used for analysis of results. ProDTMMulti is a questionnaire investigating self-perception with regard to TMD signs and symptoms in four different situations: upon waking, chewing, talking and at rest. In each situation, individuals shall answer to 10 questions investigating signs and symptoms commonly observed in TMD, based on a numerical scale from zero (absence of sign or symptom) to 10 (most severe possible). Scores may vary, considering the sum of each sign and symptom in the four situations, from zero to $400^{12,13}$.

Students were gathered in a room where explanations were given about the objective of the study and the way they should answer the questionnaires. Participants had 15 minutes to answer the questionnaires and, in case of doubts, they were immediately explained. Investigators responsible for the application were present in the room during the whole process. To MBI-SS, questions regarding exclusion criteria were added, being that questionnaires were numbered according to the number of students agreeing to participate in the study; so there has been no identification of subjects. Students meeting exclusion criteria had their questionnaires removed from the sample after application, without public exposure of their health history, thus preventing any embarrassment.

\section{Statistical analysis}

A descriptive statistical analysis was initially performed for ProDTMMulti and MBI-SS scores. To compare BS dimensions between genders, non-parametric statistics was used (Mann-Whitney test). To evaluate correlation between TMD signs and symptoms and BS dimensions, Spearman Correlation Test was used. ANOVA One Way was also used to identify variation between BS dimensions scores along the years by gender. Significance level was $5 \%$.
The study was approved by the Research Ethics Committee, FORP/USP, under protocol 24347113.7.0000.5419.

\section{RESULTS}

In the beginning of the study, 72 students of the first year (2013) were included. In the second application, 12 students have withdrawn, so in 2014, 60 students have participated in the study. In 2015, 12 more students have withdrawn, that is, 58 have answered the questionnaires. Figure 1 shows the flowchart with sample composition progression along the study.

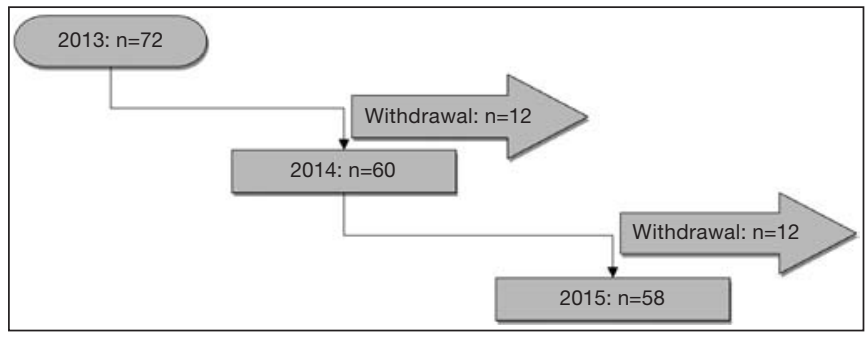

Figure 1. Flowchart of students participation progression along the years 2013, 2014 e 2015

According to criteria established/described by Loretto, Martins $\&$ Abatayguara ${ }^{26}$, indicative of presence, risk or absence of BS was evaluated (Table 1). The analysis of data collected in this sample has shown increased frequency of indicative of presence of the syndrome as time went by and fluctuation with regard to risk and its absence. The percentage of females in the risk zone for developing BS was higher as compared to males in all evaluated years, being that for both genders in the first and third year of the course, there has been higher risk as compared to the second year (females 2013: 31\%, 2014: 24\%, 2015: 37\%; males - 18\%, 2014: 9\%, 2015: 18\%).

It is also relevant to highlight that for females there has been a mild increase in risk percentage when comparing first and third years, while for males these values were maintained stable. The frequency of absence of syndrome has dropped for both genders in the last evaluation year.

Table 1. Absolute value and percentage of individuals with presence, risk or absence of Burnout syndrome, according to cutoff points established by Loretto, Martins \& Abatayguara ${ }^{26}$

\begin{tabular}{llccc}
\hline Year & & Females & Males & Total \\
\hline 2013 & Presence & $2(5 \%)$ & 0 & $2(3 \%)$ \\
& Risk & $12(31 \%)$ & $4(18 \%)$ & $16(27 \%)$ \\
2014 & Absence & $24(64 \%)$ & $18(82 \%)$ & $42(70 \%)$ \\
& Presence & $3(8 \%)$ & $1(5 \%)$ & $4(7 \%)$ \\
& Risk & $9(24 \%)$ & $2(9 \%)$ & $11(18 \%)$ \\
& Absence & $26(68 \%)$ & $19(86 \%)$ & $45(75 \%)$ \\
& Presence & $4(11 \%)$ & $2(9 \%)$ & $6(10 \%)$ \\
& Risk & $14(37 \%)$ & $4(18 \%)$ & $18(30 \%)$ \\
& Absence & $20(52 \%)$ & $16(73 \%)$ & $36(60 \%)$ \\
\hline
\end{tabular}


The presence of indicative of the syndrome and of risk to develop it was higher among females in all evaluated years. Absence of BS was more frequent among males in all evaluated years. Considering total sample, there has been increase in the frequency of the presence of the syndrome from year to year; decreased frequency of risk and absence only in the last year. Descriptive analysis of the three BS dimensions was also carried out, by gender, in each evaluated year. There has been significant difference between males and females for emotional exhaustion in the three evaluated years $(p=0.002, p=0.003$, $\mathrm{p}=0.01$, respectively) and also for cynicism in the last year $(\mathrm{p}=0.02)$, being higher for females (Table 2).

There have been variations on scores obtained along the years for each evaluated dimension, between males and females. There has been CI decrease and professional effectiveness increase for females in the years 2013 and 2014; increase in professional effectiveness from 2013 to 2015, and increased EE

Table 2. Median, standard deviation and comparison between genders of Burnout syndrome dimensions along the years 2013, 2014 and 2015 of the dentistry course

\begin{tabular}{lcccc}
\hline & & Females & Males & p-value* \\
\hline 2013 & EE & $3.5( \pm 1.2)$ & $2.7( \pm 0.9)$ & ${ }^{* *} 0.002$ \\
2014 & DE & $2( \pm 1.8)$ & $1.8( \pm 1.7)$ & 0.65 \\
& PE & $3( \pm 0.8)$ & $2.8( \pm 0.7)$ & 0.5 \\
2015 & EE & $4( \pm 1.2)$ & $2.8( \pm 1.1)$ & ${ }^{* *} 0.003$ \\
& DE & $1( \pm 1.2)$ & $1.1( \pm 1.1)$ & 0.32 \\
& PE & $4.3( \pm 0.8)$ & $3.9( \pm 0.9)$ & 0.14 \\
& EE & $4.6( \pm 1.1)$ & $3.8( \pm 1)$ & ${ }^{* *} 0.01$ \\
& DE & $2( \pm 1.3)$ & $1.3( \pm 1.3)$ & ${ }^{* *} 0.02$ \\
& PE & $4.1( \pm 1)$ & $3.9( \pm 1)$ & 0.51
\end{tabular}

* Mann-Whitney Test (Wilcoxon Rank-Sum Test). ** Statistical significance in comparison between genders. $\mathrm{EE}=$ emotional exhaustion; $\mathrm{Cl}=$ cynicism; $\mathrm{PE}=$ professional effectiveness. and CI, returning to baseline values from 2014 to 2015; increased professional effectiveness between 2013 and 2015 and between 2014 and 2015 for males, in addition to decreased CI from 2014 to 2015 . Professional effectiveness has increased between 2013 and 2014 and between 2013 and 2015 (Table 3). Correlations between BS dimensions and total ProDTMMulti score, representing self-perception of subjects with regard to TMD signs and symptoms were tested by Spearman Correlation test. There have been correlations with EE in females of the first and second evaluated years $(p=0.0004$ and $\mathrm{p}=0.04$, respectively). There has been no correlation of ProDTMMulti with BS dimensions in any other moment or dimension, both for females and males (Table 4). Figure 2 represents annual trend charts for BS dimensions and total ProDTMMulti score, showing increase of these variables along evaluated years, being that in 2014 there has been a mild drop with significant increase in 2015.

Table 3. Variation of dimensions emotional exhaustion, cynicism and professional effectiveness of MBI-SS in comparison of years for males and females

\begin{tabular}{|c|c|c|c|c|}
\hline & & EE & DE & PE \\
\hline \multirow[t]{3}{*}{ Females } & 2013 vs 2014 & ns & $<0.05^{\star}$ & $<0.01^{*}$ \\
\hline & 2013 vs 2015 & ns & ns & $<0.05^{\star}$ \\
\hline & 2014 vs 2015 & $<0.05^{*}$ & ns & ns \\
\hline \multirow[t]{3}{*}{ Males } & 2013 vs 2014 & ns & ns & $<0.01^{*}$ \\
\hline & 2013 vs 2015 & $<0.01^{*}$ & ns & $<0.01^{*}$ \\
\hline & 2014 vs 2015 & $<0.01^{*}$ & $<0.05^{\star}$ & ns \\
\hline
\end{tabular}

Statistical test: ANOVA One Way. ${ }^{*}$ Statistical significance. EE = emotiona exhaustion; $\mathrm{Cl}=$ cynicism; $\mathrm{PE}$ = professional effectiveness.

Table 4. Correlation between perception of temporomandibular disorder signs and symptoms (ProDTMMulti) and Burnout syndrome dimensions (MBI-SS)

\begin{tabular}{lccccccc}
\hline ProDTMMulti & \multicolumn{2}{c}{ EE } & \multicolumn{2}{c}{ DE } & & PE & \\
& Males & & Females & Males & Females & Males & Females \\
\hline 2013 & $0.11(0.34)$ & $0.0004^{*}(0.54)$ & $0.57(0.12)$ & $0.46(0.12)$ & $0.6(-0.09)$ & $0.64(0.07)$ \\
2014 & $0.89(0.03)$ & $0.04^{\star}(0.32)$ & $0.46(0.16)$ & $0.36(0.15)$ & $0.38(0.19)$ & $0.27(-0.18)$ \\
2015 & $0.49(0.15)$ & $0.69(0.06)$ & $0.56(-0.12)$ & $0.88(0.02)$ & $0.90(0.02)$ & $0.31(-0.17)$ \\
\hline
\end{tabular}

Pearson Correlation test. *Statistical significance. $\mathrm{EE}=$ emotional exhaustion; $\mathrm{Cl}=$ cynicism; PE = Professional effectiveness. 


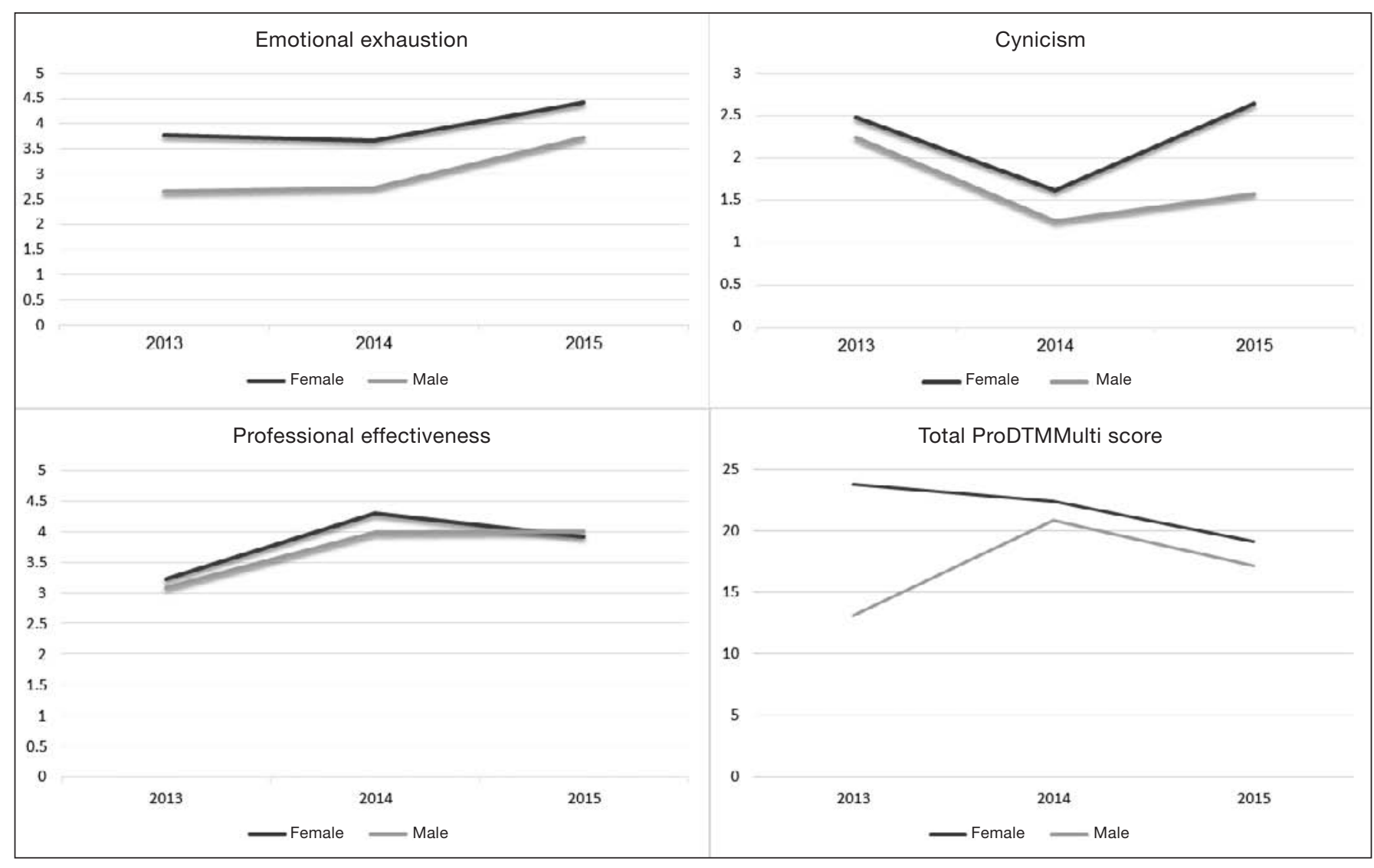

Figure 2. Annual trend for Burnout syndrome dimensions Emotional Exhaustion, Cynicism, Professional Effectiveness and total ProDTMMulti score along the years 2013, 2014 and 2015

\section{DISCUSSION}

The incidence of BS among students has been increasingly investigated by the scientific literature due to major impairment of quality of life and academic yield ${ }^{23-25}$. Among most frequently evaluated courses, health area courses are important due to the need to develop responsibilities related to the lives of third parties, with institutional and personal demands. So, it is possible an early development of BS still in this stage of academic graduation, with severe emotional consequences, such as lack of energy and enthusiasm, exhaustion sensation, lack of confidence, personal dissatisfaction and mood changes, especially in the first years ${ }^{27}$.

Previous studies have shown high BS prevalence among dentistry students and have associated MBI-SS dimensions to the possibility of quitting the course $\mathrm{e}^{22,25,28}$. This fact may be associated to the attempt to cope with pressures imposed by study, especially in the first years when there is the transition from high school to a reality full of challenges requiring autonomy and independence with maturity/responsibility. Our results have not shown a high percentage of students with indicative of the syndrome, however it is possible to state that a considerable number of students are in "presence" and "risk" ranges along investigated years, especially females. Carlotto et al. have evaluated health area students in general and had data similar to ours, with high scores for
EE, which might be considered the first indicative for BS development ${ }^{28}$.

This dimension has not reached cutoff points established by Loretto et al. ${ }^{26}$, but there has been increase in scores along the years for both genders, with higher scores for females and significantly different from male scores. The fact of being male or female is not necessarily a determining factor for emotional exhaustion. However, starting from the premise that females are socially conditioned to care and that they are more emotional, one may understand that this condition might predispose more females to the development of emotional exhaustion, which is a dimension of affective nature ${ }^{29,30}$.

Similarly, there is a female predisposition for TMD, the explanations of which are also based on similar emotional factors, in addition to hormonal factors ${ }^{23}$. Our results have shown decrease in ProDTMMulti scores along the years for females, however, they remained always higher as compared to males, which indicates that females have higher perception of TMD signs and symptoms $s^{3,31}$.

ProDTMMulti points to self-perception with regard to TMD signs and symptoms ${ }^{12,13}$, being relevant for professionals when deciding the therapeutic approach. In this sense, there has been correlation between total ProDTMMulti score and EE only for females in the years 2013 and 2014, when signs and symptoms perception was more evident, reinforcing the idea that such factors are associated. May be higher load of theo- 
retical subjects in the first years of the course, added to anxiety and concern with new responsibilities in face of dentistry course demands, might have influenced emotional aspects of these female students. In remaining BS dimensions for males, there have been no significant correlations.

Other studies have associated negative emotional states as predisposing to TMD, however a direct causality relationship has not yet been scientifically confirmed. By means of animal stress-inducing models, investigators have shown that psychological factors may play important role in the development of TMD by changes in cortisol levels, TMJ ultra and microstructures observed with electronic microscopy, by increased expression of inflammatory cytokines, substance $\mathrm{P}$ and calcitonin levels (CGRP), in addition to increased mioelectric activity of masticatory muscles ${ }^{32,33}$. However, in our sample, emotional wear due to study was not reflected in increased perception of TMD symptoms as years went by. Maybe emotional tensions release might be present when one considers this stage of life with intense social relations, because it is proven that social isolation contributes to increase stress levels and, as a consequence, to the development of chronic diseases associated to this condition ${ }^{34}$.

So, being with friends, relaxing, finding the independence of life, practicing physical activities, less sedentary lifestyle, among others, may have contributed to lower perception of TMD signs and symptoms. A study with a population of graduated dentists, involving other stages of life, such as being married, raising children and financial commitments, may show different results, such as higher scores of TMD signs and symptoms and higher prevalence of BS.

With regard to professional effectiveness, there has been trend to higher scores, which is positive, because it indicates that students consider themselves more effective in their academic duties. However, emotional exhaustion has also increased, showing that it does not decrease because students feel they are more effective, thus remaining as risk factor for BS. This indicates that course progression generates emotional overload due to imposed demands, but students consider themselves more able to perform their tasks, which in turn might stop the development of BS, together with low cynicism levels ${ }^{18,27,28}$.

This also coincides with the beginning of clinical activities which place students in contact with professional practice and generate maturity and productivity feeling for providing services to community. Post-graduation students, for example, have shown that they believe they are effective in performing their tasks and had no cynicism with regard to studies (lack of reliability of the performed activity, namely, studying ${ }^{35}$.

It is interesting to observe dimensions evolution during the evaluated period: professional effectiveness scores have increased both for females and males; cynicism remains stable for females while EE increases. And for males, CI decreases and $\mathrm{EE}$ increases, however less than for females, with significant difference in this dimension between genders in the three evaluated years. So, it seems that females face pressures and responsibilities imposed by the course with further emotional wear as compared to males.

Primary limitation of this study is the lack of clinical exams of studied population to establish diagnoses of both conditions, TMD and BS, both based on clinical criteria. Evaluation tools used are based on the subjective perception of each subject with regard to the presence of signs and symptoms, and should be complemented with more objective evaluations. However, it is important to stress the observational character of this study which intended to carry out a preliminary analysis to relate subjective perception of signs and symptoms of both evaluated conditions, up to then not described by scientific literature, in a population of dentistry students who are not looking for treatment. Next step to confirm such results will be investigation by means if clinical/research protocols which might effectively point to the presence or absence of the diseases in populations of students and workers.

\section{CONCLUSION}

In light of the above, among MBI-SS dimensions, EE was the most commonly reported by dentistry students, and it seems to be correlation between this dimension and subjective perception of temporomandibular disorder signs and symptoms among females and a fluctuation of BS scores with the progression of the course.

\section{ACKNOWLEDGMENTS}

We acknowledge the Conselho Nacional de Pesquisa (CNPq), which, by means of the Institutional Program of Scientific Initiation Scholarships (PIBIC), has financially supported the development of the study.

\section{REFERENCES}

1. Greene CS, Klasser GD, Epstein JB. Revision of the American Association of Dental Research's Science Information Statement about Temporomandibular Disorders. J Can Dent Assoc. 2010;76:a115.

2. De Leeuw R, (editor). Temporomandibular disorders. In: Orofacial Pain: Guidelines for Assessment, Diagnosis and Management. $4^{\text {th }}$ ed. Chicago, IL: Quintessence; 2010. 132-5p.

3. Progiante PS, Pattussi MP, Lawrence HP, Goya S, Grossi PK, Grossi ML. Prevalence of Temporomandibular Disorders in an Adult Brazilian Community Population Using the Research Diagnostic Criteria (Axes I and II) for Temporomandibular Disorders (The Maringá Study). Int J Prosthodont. 2015;28(6):600-9.

4. Scrivani SJ, Keith DA, Kaban LB. Temporomandibular disorders. N Engl J Med. 2008;359(25):2693-705.

5. Korszun A, Hinderstein B, Wong M. Comorbidity of depression with chronic facial pain and temporomandibular disorders. Oral Surg Oral Med Oral Pathol Oral Radiol Endod. 1996;82(5):496-500.

6. Hansdottir R, Bakke M. Joint tenderness, jaw opening, chewing velocity, and bite force in patients with temporomandibular joint pain and matched healthy control subjects. J Orofac Pain. 2004;18(2):108-13.

7. Knutsson K, Hasselgren G, Nilner M, Petersson A. Craniomandibular disorders in chronic orofacial pain patients. J Craniomandib Disord. 1989;3(1):15-9.

8. McCreary CP, Clark GT, Merril RL, Flack V, Oakley ME. Psychological distress and diagnostic subgroups of temporomandibular disorder patients. Pain. 1991;44(1):29-34.

9. Gatchel RJ, Garofalo JP, Ellis E, Holt C. Major psychological disorders in acute and chronic TMD: an initial examination. J Am Dent Assoc. 1996;127(9):1365-74.

10. Jones DA, Rollman GB, Brooke RI. The cortisol response to psychological stress in temporomandibular dysfunction. Pain. 1997;72(1-2):171-82.

11. Geissler PR. An investigation of the stress factor in the mandibular dysfunction syndrome. J Dent. 1985;13(4):283-7.

12. de Felicio CM, Mazzetto MO, de Silva MA, Bataglion C, Hotta TH. A preliminary 
protocol for multi-professional centers for the determination of signs and symptoms of temporomandibular disorders. Cranio. 2006;24(4):258-64.

13. De Felicio CM, Melchior M de O, Da Silva MA. Clinical validity of the protocol for multi-professional centers for the determination of signs and symptoms of temporomandibular disorders. Part II. Cranio. 2009;27(1):62-7.

14. Maslach C, Schaufeli WB, Leiter MP. Job burnout. Annu Rev Psychol. 2001;52:397-422.

15. Caballero Martín M, Bermejo Fernández F, Nieto Gómez R, Caballero Martínez F. [Prevalence and factors associated with burnout in a health área]. Aten Primaria. 2001;27(5):313-7. Spanish.

16. Atance Martínez JC. [Epidemiologic aspects of the burnout syndrome in hospital personnel]. Rev Esp Salud Publica. 1997;71(3):293-303. Spanish

17. Benevides-Pereira AMT, (organizador). Burnout: quando o trabalho ameaça o bem-estar do trabalhador. Sáo Paulo: Casa do Psicólogo; 2002.

18. Schaufeli WB, Martinez IM, Pinto AM, Salanova M, Bakker AB. Burnout and engagement in university students - a cross-national study. J Cross Cult Psychol. 2002;33(5):464-81.

19. Cunradi CB, Greiner BA, Ragland DR, Fisher JM. Burnout and alcohol problems among urban operators in San Francisco. Addict Behav. 2003;28(1):91-109.

20. Samuelsson M, Gustavsson JP, Petterson IL, Arnetz B, Asberg M. Suicidal feelings and work environment in psychiatric nursing personnel. Soc Psychiatry Psychiatr Epidemiol. 1997;32(7):391-7.

21. Vieira I, Ramos A, Martins D, Bucasio E, Benevides-Pereira AM, Figueira I, et al. Burnout na clínica psiquiátrica. relato de um caso. Rev Psiquiatr. 2008;28(3):352-6.

22. Campos JA, Maroco J. [Maslach Burnout Inventory, student survey: Portugal-Brasil cross-cultural adapatation]. Rev Saude Publica. 2012;46(5):816-24. Portuguese.

23. Campos JA, Jordani PC, Zucoloto ML, Bonafé FS, Maroco J. Burnout syndrome among dental students. Rev Bras Epidemiol. 2012;15(1):155-65.

24. Humphris G, Blinkhorn A, Freeman R, Gorter R, Hoad-Reddick G, Murtomaa H, et al. Psychological stress in undergraduate dental students: baseline results from seven European dental schools. Eur J Dental Educ. 2002;6(1):22-9.

25. Pöhlmann K, Jonas I, Ruf S, Harzer W. Stress, burnout and health in the clinical period of dental education. Eur J Dental Educ. 2005;9(2):78-84

26. Loretto NR, Martins IA, Abatayguara MM. Burnout em estudantes de odontologia: coorte comparativa de dois modelos curriculares. Odontol Clín-Cient. 2011;10(2):147-52.

27. Alemany Martínez A, Berini Aytés L, Gay Escoda C. The burnout syndrome and associated personality disturbances. The study in three graduate programs in Dentistry at the University of Barcelona. Med Oral Patol Oral Cir Bucal. 2008;13(7):444-50.

28. Carlotto MS, Nakamura AP, Câmara SG. Síndrome de Burnout em estudantes universitários da área da saúde. Psico. 2006; 37(1):57-62.

29. Tamayo A. Exaustão Emocional no trabalho. Rev Administr. 2002;37(2):26-37.

30. Matos AA, Deusdedit Junior M. The incorporation of gender in the study of Burnout Syndrome. Unimontes Científica. 2008;10(1/2):25-33.

31. Kim TY, Shin JS, Lee J, Lee YJ, Kim MR, Ahn YJ, et al. Gender difference in associations between chronic temporomandibular disorders and general quality of life in Koreans: a cross-sectional study. PLoS One. 2015;10(12):e0145002.

32. Wu G, Chen L, Zhu G, Su Y, Chen Y, Sun J, Wang Y. Psychological stress induces alterations in temporomandibular joint ultrastructure in a rat model of temporomandibular disorder. Oral Surg Oral Med Oral Pathol Oral Radiol Endod. 2011;112(6):e106-12.

33. Wu G, Chen L, Fei H, Su Y, Zhu G, Chen Y. Psychological stress may contribute to temporomandibular joint disorder in rats. J Surg Res. 2013;183(1):223-9.

34. Koshoridze N, Kuchukashvili Z, Menabde K, Lekiashvili Sh, Koshoridze M. alterations in brain creatine concentrations under long-term social isolation (experimental study). Georgian Med News. 2016;(251):70-7.

35. Silva AH, Vieira KM. Burnout Syndrome in graduate students: analysis of the influence of self-esteem and relationship advisor-advisee. Pretexto. 2015;16(1):52-68. 